\title{
Effect of hydrogen peroxide on the biodegradation of PCBs in anaerobically dechlorinated river sediments
}

\author{
Paul J. Anid, Beatriz P. Ravest-Webster \& Timothy M. Vogel \\ Environmental and Water Resources Engineering, Department of Civil and Environmental Engineering, \\ The University of Michigan, Ann Arbor, Michigan, USA
}

Received 1 September 1992; accepted in revised form 23 April 1993

Key words: aerobic, anaerobic, biodegradation, hydrogen peroxide, polychlorinated biphenyls, sequential

\begin{abstract}
The ability to initiate aerobic conditions in dechlorinated anaerobic sediments was tested using hydrogen peroxide as an oxygenation agent. Hydrogen peroxide additions to the sediment induced aerobic polychlorinated biphenyl (PCB) degraders as indicated first, by an increase in bacterial count and second by a decline in PCB concentration from $135 \mu \mathrm{g} / \mathrm{g}$ to $20 \mu \mathrm{g} / \mathrm{g}$ over a 96-day period. Dechlorinated anaerobic sediment seems also to harbor indigenous anaerobic and aerobic microorganisms with high PCB degradation abilities. Those results support the potential of in situ degradation of PCBs using a sequential anaerobic-aerobic technique.
\end{abstract}

\section{Introduction}

Polychlorinated biphenyls (PCBs) are a group of chlorinated hydrocarbons that were produced and used on a large scale before they were banned in 1977 , due in part to their tendency to accumulate in sediments, water and biota. However, more than $35 \%$ of the one-half billion kilograms of manufactured PCBs are estimated to be present in the global ecosystem (NAS 1979). Oceanic waters alone hold $80 \%$ of PCBs present in the mobile environmental reservoir, whereas river sediments constitute the other major sink for disposed PCBs (NAS 1979). For example, local concentrations of PCBs in sediments can reach levels in excess of $50 \mu \mathrm{g} / \mathrm{g}$ (Weaver 1984; Brown et al.1985). The average concentration in the Hudson River sediment (NY), is $\sim 10 \mu \mathrm{g} / \mathrm{g}$ (Bopp et al. 1981).

The physical and chemical properties that made PCBs ideal for industrial applications allow them to persist in the environment and because none of the PCB congeners are synthesized in nature, they were not expected to be readily biodegradable. However, this view has been altered by observations of metabolic alterations of PCBs in the environment (Brown et al.1984). For example, laboratory studies have shown that certain PCB congeners can be partially dechlorinated under anaerobic conditions (Quensen et al. 1988), and oxidized by aerobic mixed and pure microbial cultures (Bedard et al. 1986, 1987; Bopp 1984; Focht \& Brennan 1985; Furukawa et al. 1979). Generally, anaerobic microbes reduce the chlorine number through reductive dechlorination and aerobic microbes oxidize PCBs by the addition of oxygen to a biphenyl ring. Reductive dechlorination is the replacement of a chlorine substituent by a hydrogen and the departure of chlorine as chloride ion.

In many systems, anaerobic reductive dechlorination rates decrease with decreasing chlorine number, and aerobic oxidation rates increase with decreasing chlorine number (Vogel et al. 1987). Highly chlorinated congeners are less susceptible to aerobic degradation because of their high redox po- 
tentials, whereas low chlorinated congeners are more reduced and therefore susceptible to oxidation. For PCB congeners, location of chlorine, and not just number influence dechlorination and oxidation. The complete degradation process might therefore require sequential anaerobic dechlorination and aerobic mineralization. Evidence of natural anaerobic PCB degradation, discovered when the congener distribution pattern was noted to have changed from the original Aroclor 1242 in Hudson River sediment (Brown et al. 1984), provides evidence for the potential for in situ degradation. Many locations in the Hudson River have levels of PCBs indicative of an extensive natural reductive dechlorination activity. For such partially dechlorinated sediments, the most critical parameter for in situ remediation might be the transition from anaerobic to aerobic conditions in order to stimulate the indigenous aerobic PCB-degraders. This is often done by adding pure oxygen or hydrogen peroxide $\left(\mathrm{H}_{2} \mathrm{O}_{2}\right)$. A disadvantage of using pure oxygen, however, is related to operational problems associated with the delivery and oxygen chemistry in the sediments. Oxygen has a limited solubility in water ( $\sim 10 \mathrm{mg} / \mathrm{l}$ under $1 \mathrm{~atm}$ of air and $\sim 40 \mathrm{mg} / 1$ from 1 atm $\mathrm{O}_{2}$ ). Some subsurface in situ remediation schemes use $\mathrm{H}_{2} \mathrm{O}_{2}$ as a source of oxygen because of its high aqueous solubility and better perfusion characteristics. Recent studies have shown, however, that $\mathrm{H}_{2} \mathrm{O}_{2}$ can be toxic to some subsurface microorganisms at concentrations as low as $0.003 \%$ (Pardieck et al. 1990), although mixed biofilm cultures were shown to tolerate $\mathrm{H}_{2} \mathrm{O}_{2}$ concentrations up to $0.2 \%$ (Britton 1985).

The Hudson River sediments represent, with their history of PCB contamination, ideal material for testing the feasibility of the anaerobic-aerobic bioremediation technique. The objective of this research was to use Hudson River sediment to determine whether PCBs can be mineralized under sequential anaerobic-aerobic conditions following substrate addition to enhance each process. Several aspects are explored here including the ability to initiate aerobic conditions in anaerobic sediment using hydrogen peroxide as an oxygenation agent and the occurrence of indigenous aerobes in the sediment capable of degrading PCBs.

\section{Materials and methods}

\section{Oxygenation of the anaerobic sediments}

The sediment was sampled from a dechlorinated site (H7) located at mile point 193.5 between Rogers Island and Billings Island on the Hudson river in the state of New York. The sediment had an initial congener distribution that indicated the previous occurrence of PCB dechlorination. The background concentration was $\sim 5 \mu \mathrm{g} / \mathrm{g}$ of total PCBs, $80 \%$ of which consisted of 2-monochlorobiphenyl and 2,2'- and 2,6-dichlorobiphenyl. The wet sediment $(0.8 \mathrm{t})$ was then amended with additional Aroclor $1242(300 \mu \mathrm{g} / \mathrm{g})$ (neat from vial, then washed with methanol) in individual buckets that were afterwards poured in a glass reactor. Anaerobic conditions in the reactor were then induced by adding methanol in four increments of $6.67 \mathrm{mg} \mathrm{MeOH} / \mathrm{g}$ sediment/week, along with a mineral media through injection wells connected to a multi-channel pump. To monitor dechlorination, samples of sediments were collected each month through top access ports and analyzed. A more detailed description is given elsewhere (Anid et al. 1991).

For the purpose of the oxygenation experiment, three random grabs were taken from the reactor after 76 weeks of anaerobic treatment and mixed, forming a composite sample that had a PCB concentration of $135 \mu \mathrm{g} / \mathrm{g}$. The sediment had a mole percent homolog distribution indicative of an extensive dechlorination. Di-, tri-, tetra-, penta-, and hexachlorobiphenyl homologs had decreased by $11 \%, 73 \%, 66 \%, 73 \%$, and $94 \%$ respectively, versus a $76 \%$ increase in the monochlorobiphenyl homologs at the end of the 76-week anaerobic treatment. Incubations were prepared by mixing $5 \mathrm{~g}$ (wet weight) of the composite sample with $31 \mathrm{ml}$ water in 120-ml serum bottles sealed with teflon coated septa. Mixing was performed under continuous nitrogen flushing for $10 \mathrm{~min}$. Hydrogen peroxide was then added to duplicate bottles at concentrations of 0,171 (controls), 514 ( 2 additions $\times 257$, at days 0 and $60), 686$ ( 2 additions $\times 343$, at days 0 and 60 ), 857 ( 2 additions $\times 429$, at days 0 and 60 ) and $1714 \mathrm{mg}$ per liter of sediment-water mixture. Bottles were kept at room temperature $\left(22^{\circ} \mathrm{C}\right)$. Oxygen levels were 
monitored by gas chromatography analysis ( $\mathrm{GC}$ series 580, GOW MAC Company, Bridgewater, $\mathrm{NJ}$ ) of the headspace throughout the 96-day experiment. During the first 30 days, oxygen monitoring was performed every 48 hours or until complete $\mathrm{O}_{2}$ depletion. During the last 66 days following more $\mathrm{H}_{2} \mathrm{O}_{2}$ addition, oxygen was monitored at four-day intervals. The rate determination for the first 30 days was therefore based on a 15 -point curve; $r^{2}$ values were between 0.866 and 0.973 . For the last 66 days, a 14-point curve was used and $\mathrm{r}^{2}$ values were between 0.840 and 0.923 . Control bottles were autoclaved three times before $\mathrm{H}_{2} \mathrm{O}_{2}$ was added, whereas another set was incubated in $\mathrm{N}_{2}$ atmosphere without $\mathrm{H}_{2} \mathrm{O}_{2}$ to check for oxygen diffusion into the bottles. Initial (30 days after first $\mathrm{H}_{2} \mathrm{O}_{2}$ addition) and final (66 days after second $\mathrm{H}_{2} \mathrm{O}_{2}$ addition) rates of oxygen consumption were determined for all incubations. The potential toxicity of hydrogen peroxide was evaluated by enumerating bacterial cells in the sediment at beginning and end of the 96-day experiment. Nutrient agar plates were used for this purpose. The levels of PCBs were also determined before and after hydrogen peroxide additions in all bottles. Procedure for PCB extraction and analysis is described elsewhere (Nies \& Vogel 1990).

\section{Isolation of aerobic PCB degraders}

PCB degraders from the dechlorinated sediment were isolated by analog enrichment, using biphenyl and Aroclor 1221. Dechlorinated sediment, sampled after 40 weeks of anaerobic treatment, was added to 1 liter Erlenmeyer flasks containing basal salts and trace metal media plus either biphenyl or Aroclor 1221 as the sole carbon source. Flasks were incubated at $30^{\circ} \mathrm{C}$ with constant aeration. Enrichments were made by sequentially transferring $10 \mathrm{ml}$ aliquots to new liquid media with increasing concentrations of Aroclor 1221 up to $50 \mathrm{mg} / \mathrm{l}$. Enrichments in biphenyl were kept at saturating conditions throughout the transfers. An increase in turbidity was used as evidence of growth in the compound. Aliquots from liquid cultures were plated on biphenyl plates and subsequently in nutrient agar to obtain single isolates. Five pure cultures were then screened for their PCB degradative competence according to the rapid essay procedure developed by Bedard et al. (1986). In this procedure, pure cultures were grown in either saturating levels of Biphenyl or in $10 \mathrm{mM}$ Sodium succinate, centrifuged at 10,000 rpm for $15 \mathrm{~min}$ and washed once in $0.005 \mathrm{M}$ phosphate buffer ( $\mathrm{pH} 7$ ). Cells were resuspended in same concentration phosphate buffer to an optical density of one $(600 \mathrm{~nm})$. Four mls of resting cell suspension was added to 20 -ml vials containing a final concentration of $5 \mu \mathrm{M}$ of PCB congener mix, previously added in acetone solution (Table 4). One control consisted of non-inoculated congener mix and the other contained sulfuric acid killed cells. Vials with Teflon lined screw caps were incubated for $48 \mathrm{~h}$ at $30^{\circ} \mathrm{C}$ in a gyratory shaker. Following incubation, the mixture was extracted and analyzed for PCB content according to the procedure described elsewhere (Nies \& Vogel 1991).

One of the isolates (AY5) was selected to test for aerobic degradation of PCB congeners on anaerobically dechlorinated sediments obtained from the reactor. The gram negative AY5 was identified based on fatty acid analysis as a Pseudomonas cepacia. AY5 cells were grown in $10 \mathrm{mM}$ sodium succinate, centrifuged and resuspended, as described above, and incubated in one gram wet weight of dechlorinated sediments instead of the $5 \mu \mathrm{M}$ congener mix. PCB degradation ability of AY 5 was compared to that of controls containing sulfuric acid killed cells and to that of non-inoculated sediments. After 48 hours, samples were extracted and analyzed for PCB content.

\section{Results and discussion}

\section{Oxygenation of the anaerobic sediments}

The average chlorine number per biphenyl in the partially dechlorinated anaerobic sediment used in the oxygenation experiment, was 1.81 after 76 weeks of anaerobic treatment (versus 3.34 at time 0 ). Meta- and para-chlorines were reduced by $81 \%$ whereas ortho-chlorines were reduced by only $11.7 \%$ for the same period. However, this apparent reduction in ortho-chlorines might not reflect a 
Table 1. Oxygen consumption first-order rate constant $(\mathrm{k})$ and percent oxygen consumed in incubations after first ${ }^{\mathrm{a}}$ and second $\mathrm{d}^{\mathrm{b}}$ addition of hydrogen peroxide to dechlorinated anaerobic sediment.

\begin{tabular}{lllll}
\hline $\begin{array}{l}\mathrm{H}_{2} \mathrm{O}_{2} \text { added } \\
\text { per bottle } \\
(\mathrm{mg})\end{array}$ & $\begin{array}{l}\text { Initial } \mathrm{k} \\
\left(\text { day }^{-1}\right)\end{array}$ & $\begin{array}{l}\text { Percent } \mathrm{O}_{2} \\
\text { consumed }\end{array}$ & $\begin{array}{l}\text { Final } \mathrm{k} \\
\left(\text { day }^{-1}\right)\end{array}$ & $\begin{array}{l}\text { Percent } \mathrm{O}_{2} \\
\text { consumed }\end{array}$ \\
\hline $171^{\mathrm{c}}$ controls & 0.006 & 0 & 0.006 & 0 \\
$514^{\mathrm{d}}$ active & 0.120 & 95 & 0.03 & 60 \\
$686^{\mathrm{d}}$ active & 0.138 & 100 & 0.013 & 55 \\
$857^{\mathrm{d}}$ active & 0.159 & 95 & 0.009 & 54 \\
$1714^{\mathrm{e}}$ active & - & - & 0.017 & 72
\end{tabular}

${ }_{\mathrm{a}, \mathrm{b}}$ Initial rates correspond to oxygen consumption after the first addition of hydrogen peroxide. $\mathrm{O}_{2}$ was depleted after 30 days. Final rates correspond to oxygen consumption after the second hydrogen peroxide addition. $\mathrm{O}_{2}$ was not depleted after 66 days. ${ }^{c}$ Autoclaved bottles, hydrogen peroxide added in one increment.

Added in two increments.

${ }^{\mathrm{e}}$ Added in one increment.

novel mechanism for ortho-substituted PCB removal from the Hudson River sediments. Earlier results show accumulation rather than reduction of those ortho chlorinated mono-, and dichlorobiphenyls from anaerobic incubations (Brown et al. 1987; Quensen et al. 1988; Nies \& Vogel 1990). In any case, the more significant decrease in meta- and parachlorines reflects the advantage of dechlorination in reducing those highly chlorinated congeners considered most toxic among PCBs (Safe et al. 1985).

Upon addition of hydrogen peroxide to the dechlorinated sediment, all incubations showed an initial level of oxygen formed that was proportional to the added concentration of $\mathrm{H}_{2} \mathrm{O}_{2}$. Also, the time needed for the complete depletion of the oxygen depended on the starting $\mathrm{H}_{2} \mathrm{O}_{2}$ concentrations. Ox- ygen disappeared first in bottles with the lowest levels of added $\mathrm{H}_{2} \mathrm{O}_{2}$, and last in bottles receiving the highest dose. In addition, the rates of oxygen utilization in all bottles were proportional to the added amount of hydrogen peroxide (Table 1). For example, during the first 30 days, the oxygen consumption first-order rate constant, $\mathrm{k}$, varied between $0.120 \mathrm{~d}^{-1}$ and $0.159 \mathrm{~d}^{-1}$ upon the first incremental addition of $\mathrm{H}_{2} \mathrm{O}_{2}$. During the same period, almost all oxygen was consumed. Upon the second addition of $\mathrm{H}_{2} \mathrm{O}_{2}$, $\mathrm{k}$ values dropped significantly but remained higher than the $\mathrm{k}$ value of the autoclaved controls $\left(0.006 \mathrm{~d}^{-1}\right)$. During that period of 66 days (following the second $\mathrm{H}_{2} \mathrm{O}_{2}$ addition), $60 \%$ or less oxygen was consumed. The incubations that received $1714 \mathrm{mg}$ of $\mathrm{H}_{2} \mathrm{O}_{2}$ in one increment had the highest overall oxygen consumption during the total 96-day period. Since the autoclaved controls showed a very limited oxygen depletion, one can assume that oxygen utilization in live bottles was essentially due to biotic processes. The biological nature of oxygen consumption was also confirmed by the inhibition of oxygen utilization after active bottles were autoclaved.

Relative to autoclaved controls, microbial counts remained unchanged in incubations without $\mathrm{H}_{2} \mathrm{O}_{2}$, but increased in $\mathrm{H}_{2} \mathrm{O}_{2}$-amended bottles over the 96 day period (Table 2). Those results suggest that hydrogen peroxide, even at the highest concentration added $(0.171 \%)$, does not inhibit microbial activity in the sediments. Other studies have shown similar tolerance to high $\mathrm{H}_{2} \mathrm{O}_{2}$ concentrations in biofilm cultures (Britton 1985) but not in suspended mixed cultures (Pardieck et al. 1992). Possible reasons for the apparent tolerance are an increase in specific activities of catalase of the microorganisms or

Table 2. Effect of hydrogen peroxide additions on aerobic bacterial counts in bottles ${ }^{\mathrm{a}}$ containing previously anaerobic sediment.

\begin{tabular}{|c|c|c|c|c|c|c|}
\hline \multirow[t]{2}{*}{ Time days } & \multicolumn{6}{|c|}{ Hydrogen peroxide added per bottle (mg/l of sediment-water mixture) } \\
\hline & 0 & $171^{b}$ & 514 & 686 & 857 & 1714 \\
\hline & \multicolumn{6}{|c|}{ Cell counts $($ cells $/ \mathrm{ml})$} \\
\hline 0 & $3.5 \times 10^{5}$ & $3.5 \times 10^{5}$ & $3.5 \times 10^{5}$ & $3.5 \times 10^{5}$ & $3.5 \times 10^{5}$ & $3.5 \times 10^{5}$ \\
\hline 96 & $2.6 \times 10^{5}$ & 0.8 & $1.2 \times 10^{6}$ & $1.0 \times 10^{6}$ & $2.5 \times 10^{6}$ & $1.6 \times 10^{6}$ \\
\hline
\end{tabular}

\footnotetext{
${ }^{\mathrm{a}}$ Bottles contained $5 \mathrm{~g}$ sediment and $31 \mathrm{ml}$ water.

${ }^{\mathrm{b}}$ Bottles autoclaved before hydrogen peroxide addition.
} 


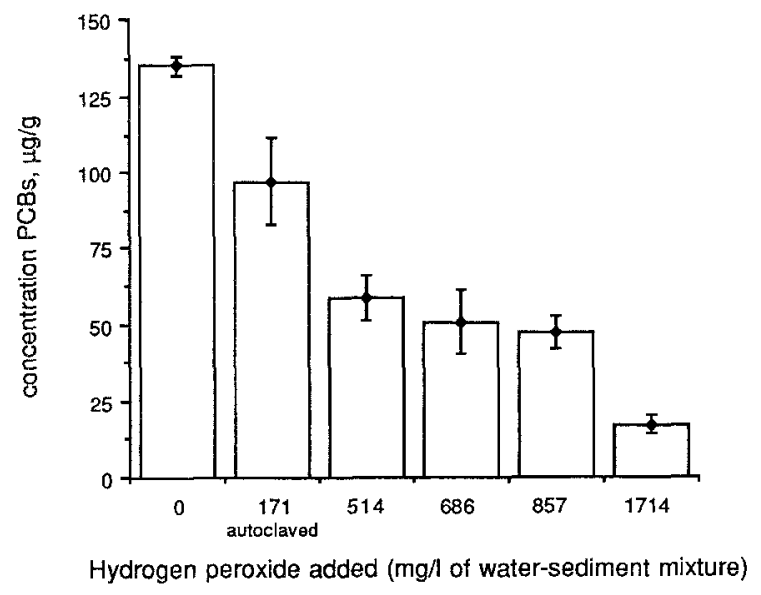

Fig. 1. Effect of hydrogen peroxide additions on the degradation of PCBs in bottles containing dechlorinated anaerobic Hudson River sediments.

growth in the numbers of catalase-positive microorganisms in the biofilm (Pardieck et al. 1992).

In parallel, the level of hydrogen peroxide added affects the extent of transformation of PCBs in the oxygenated sediments. More PCBs are degraded when $\mathrm{H}_{2} \mathrm{O}_{2}$ doses are increased. At the highest dose of $\mathrm{H}_{2} \mathrm{O}_{2}$, the PCB concentration $(\mu \mathrm{g} / \mathrm{g})$ was reduced by $85 \%$ during the 96 -day period of aerobic incubation (Fig. 1). Ortho-chloro substituted congeners, believed to be relatively resistant to oxidation ( $\mathrm{Fu}-$ rukawa et al. 1983) were also significantly reduced by $\mathrm{H}_{2} \mathrm{O}_{2}$ addition (Table 3 ). Those congeners (i.e., 2; $2,2^{\prime} ; 2,6 ; 2,4^{\prime} ; 2,3$; etc) are major products of the de-

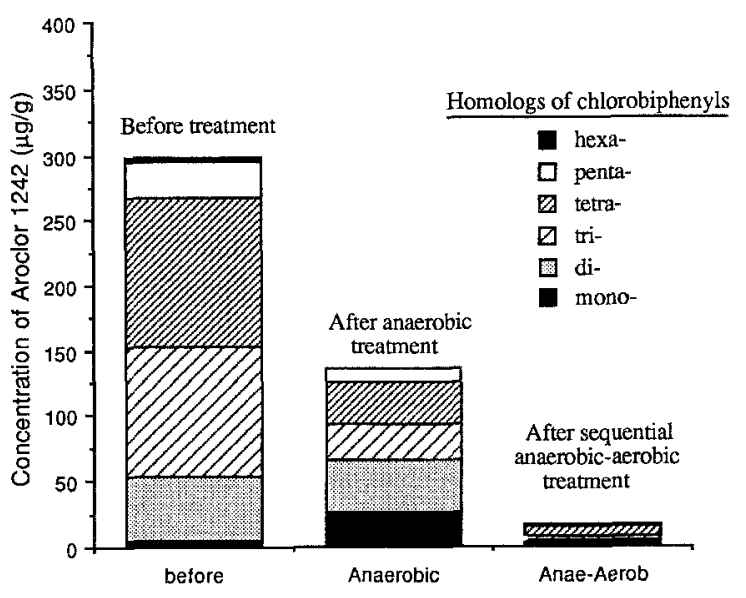

Fig. 2. Effect of sequential anaerobic-aerobic treatment on the total mass concentration of PCBs after 76 weeks of anaerobic treatment and 96-day aerobic incubation of Hudson River sediment.

chlorinated sediments. Tri- and tetra- (ortho-chloro containing) PCBs were slightly less degraded. Expectedly, more than $90 \%$ of the total mass of PCB remaining after the sequential process consisted of those highly chlorinated congeners, (i.e., trichlorobiphenyls and higher homologs) that were not completely dechlorinated at the end of the anaerobic phase. However, at this stage, their mass concentration $(\mu \mathrm{g} / \mathrm{g})$ declined by $95 \%$ compared to their concentration before treatment. For example, at the end of the sequential process, the concentration of pentachlorobiphenyls and hexachlorobiphenyls

Table 3. Change in concentration of selected ortho-chloro-substituted congeners after aerobic ${ }^{\mathrm{a}}$ treatment of anaerobic sediment.

\begin{tabular}{llllll}
\hline IUPAC number Congener name & $\begin{array}{l}\text { Concentration after } \\
\text { anaerobic treatment } \\
(\mu \text { mole/l) }\end{array}$ & $\begin{array}{l}\text { Mole concentration after } \\
\text { both anaerobic-aerobic } \\
\text { treatment in active bottles } \\
(\mu \text { mole/l) }\end{array}$ & $\begin{array}{l}\text { Percent reduction } \\
\text { (active bottles) }\end{array}$ & $\begin{array}{l}\text { Percent reduction } \\
\text { (autoclaved } \\
\text { controls) }\end{array}$ \\
\hline 1 & 2, & 12.0 & 1.02 & 91.5 & 50.0 \\
4,10 & $2,2^{\prime} ; 2,6$ & 13.5 & 0.77 & 94.3 & 54.8 \\
8,5 & $2,4^{\prime} ; 2,3-$ & 3.45 & 0.03 & 99.1 & 6.0 \\
19 & $2,2^{\prime}, 6$ & 1.80 & 0.31 & 82.7 & 26.0 \\
18 & $2,2^{\prime}, 5$ & 0.95 & 0.00 & 100 & 51.0 \\
17 & $2,2^{\prime}, 4$ & 0.61 & 68.0 & 0.0 \\
24,27 & $2,3,6 ; 2,3^{\prime}, 6$ & 1.94 & 0.14 & 87.0 & 9.0 \\
16,32 & $2,2^{\prime}, 3 ; 2,4^{\prime}, 6$ & 0.92 & 0.09 & 80.0 & 10.0 \\
52 & $2,2^{\prime}, 5,5^{\prime}$ & 1.20 & 0.24 & 73.0 & 10.0 \\
49 & $2,2^{\prime}, 4,5^{\prime}$ & 0.93 & 0.25 & & 0.0
\end{tabular}

\footnotetext{
a Adition of $0.171 \%$ Hydrogen peroxide.
} 
homologs was only $1.4 \%$ and $7 \%$ respectively, of their initial concentration.

Relative to the initial concentration of Aroclor $1242(\sim 300 \mu \mathrm{g} / \mathrm{g})$, the combined anaerobic-aerobic processes resulted in a $95 \%$ decrease in the total PCB mass (Fig. 2). Reductive dechlorination should not theoretically affect the sediment PCBs mole concentration ( $\mu$ mole/g of sediment), but their mass concentration will decrease ( $\mu \mathrm{g} / \mathrm{g}$ of sediment). The decrease is expected since an average 1.53 chlorines per biphenyl molecule were lost as a result of the anaerobic treatment. Therefore, assuming mole balance, the total mass should drop from $300 \mu \mathrm{g} / \mathrm{g}$ to $\sim 232 \mu \mathrm{g} / \mathrm{g}$ based solely on mass loss during chlorine atom removal. The aerobic phase clearly reduced both the mole concentration and mass concentration although an apparent shift of the remaining PCBs to higher chlorinated congeners occurs as the less chlorinated congeners are more biodegraded.

\section{Isolation of aerobic PCB degraders and sequential anaerobic-aerobic degradation}

The likelihood that some of the aerobic microbes counted in the oxygenation experiment possess a PCB degradative capability was indirectly tested by

Table 4. Rapid assay degradation of PCBs by biphenyl-grown microorganisms isolated from the anaerobic sediment. (percent degradation is relative to controls after 48 hours) ${ }^{\text {a.b,c }}$.

\begin{tabular}{|c|c|c|c|c|c|c|}
\hline \multirow{2}{*}{$\begin{array}{l}\text { IUPAC } \\
\text { number }\end{array}$} & \multirow[b]{2}{*}{ Congener } & \multicolumn{5}{|c|}{ ISOLATES } \\
\hline & & AY5 & AB201 & AB202 & AB203 & A204 \\
\hline 4 & $2,2^{\prime}$ & 100 & 11 & 41 & 29 & 96 \\
\hline 5 & 2,3 & 100 & 99 & 100 & 100 & 100 \\
\hline 15 & $4,4^{\prime}$ & 17 & 96 & 94 & 94 & 47 \\
\hline 53 & $2,2^{\prime}, 5,6^{\prime}$ & 87 & 0 & 0 & 0 & 97 \\
\hline 52 & $2,2^{\prime} 5,5^{\prime}$ & 95 & 0 & 0 & 0 & 98 \\
\hline 49 & $2,2^{\prime}, 4,5^{\prime}$ & 93 & 0 & 0 & 0 & 98 \\
\hline 47 & $2,2^{\prime}, 4,4^{\prime}$ & 56 & 0 & 0 & 0 & 74 \\
\hline 80 & $3,3^{\prime}, 5,5^{\mathrm{b}}$ & 0 & 0 & 0 & 0 & 0 \\
\hline 77 & $3,3^{\prime} 4,4^{\prime}$ & 0 & 11 & 0 & 22 & 23 \\
\hline 153 & $2,2^{\prime}, 4,4^{\prime}, 5,5^{\prime}$ & 23 & 0 & 0 & 0 & 20 \\
\hline
\end{tabular}

a Degradation of less than $10 \%$ relative to control is not considered significant and is shown as $0 \%$.

${ }^{\mathrm{b}}$ Internal standard not added until time of extraction.

${ }^{\mathrm{c}}$ No degradation in non-inoculated sediments.

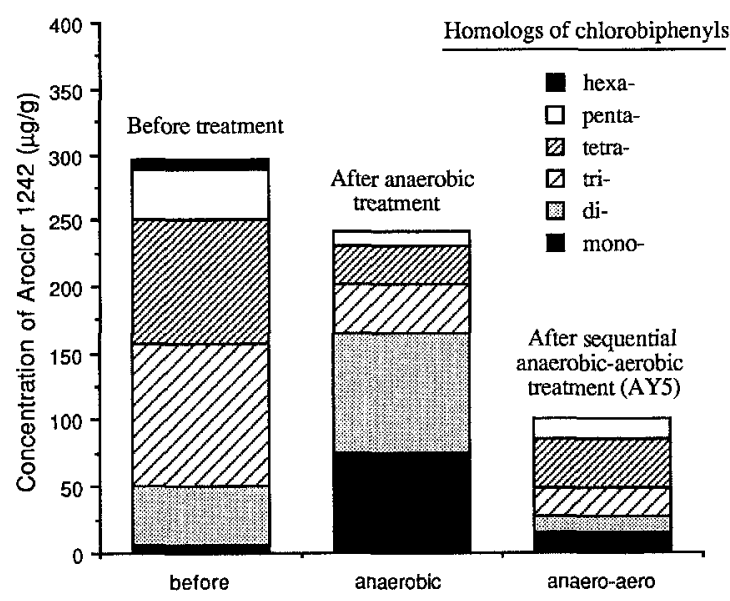

Fig. 3. Effect of sequential anaerobic-aerobic treatment on the total mass concentration of PCBs in Hudson River sediment after 40 weeks of anaerobic treatment and 48 -hr aerobic incubation with AY5 organism.

isolating biphenyl and Aroclor 1221-degrading microorganisms from the dechlorinated reactor sediments. All five pure cultures isolated on biphenyl and Aroclor 1221 were capable of degrading dichlorobiphenyls. Two of the isolates, AY5 and A204, were also capable of degrading tetrachlorobiphenyls (Table 4). It is likely that the organisms, whether grown on biphenyl or on biphenyl rich Aroclor (i.e., Aroclor 1221), will degrade those highly chlorinated congeners through a cometabolic process.

Upon adding AY5 isolate to dechlorinated sediments, a substantial reduction in the mono-, and dichlorobiphenyls concentrations was observed relative to the control, whereas no degradation was observed in non-inoculated vials. The mole distribution of Aroclor 1242 before dechlorination, after 40 weeks of anaerobic treatment, and following a sequential anaerobic-aerobic biodegradation (in vials with AY5 isolate) show a decrease in the tri-, tetra-, penta-, and hexachlorobiphenyl homologs at the end of the anaerobic phase, whereas significant degradation of all mono-, and dichlorobiphenyl homologs occurred after the sequential process (Fig. 3). Overall, the anaerobic process, followed by a 48hr aerobic degradation using a competent organism, reduced the total PCB mass concentration $(\mu \mathrm{g} / \mathrm{g})$ by $67 \%$. 


\section{Summary and conclusions}

The Hudson River sediment used in this study seemed to harbor indigenous anaerobic and aerobic microorganisms with PCB degradative capabilities. Hydrogen peroxide addition as an oxygenation agent also induced aerobic PCB degraders, as indicated first by an increase in general bacterial counts in $\mathrm{H}_{2} \mathrm{O}_{2}$ amended sediments and second, by an $85 \%$ decline in $\mathrm{PCB}$ concentration after $\mathrm{H}_{2} \mathrm{O}_{2}$ addition. The decline in the total mass of PCB as a sole result of reductive dechlorination during the anaerobic phase adds to the advantage of the twoprong engineered system. The first, the anaerobic phase, removes chlorine atoms and also reduces the PCB mass concentration by $\sim 20 \%$, and the second, the aerobic phase oxidizes the products of dechlorination and leads to a $95 \%$ reduction in the mass of PCBs. Although, the same processes might be occurring naturally in PCB-contaminated sediment, it is unlikely that both processes (anaerobic and aerobic) are important at one site. For example, estimates show a substantial decline in the total PCB mass over five years due to anaerobic dechlorination in the Hudson River sediment (Abramowicz et al. 1991). These observations, and the results of this study, provide further evidence on the feasibility of in situ enhancement of sequential reductive dechlorination and oxidation of PCBs.

Our results, however, raise some issues ranging from microbial ecology to designing an engineered in situ remedial technique for PCB destruction. It is still unclear how the utilization of oxygen, added as hydrogen peroxide to the sediment, relates to $\mathrm{PCB}$ transformation. Upon respiking with hydrogen peroxide, oxygen consumption decreased significantly compared to the first addition where all of the oxygen was depleted. Yet, some PCBs remained in the sediments. One possible explanation is that PCB degradation depends on the oxidation of naturally present co-substrates that were rapidly depleted from the sediment upon $\mathrm{H}_{2} \mathrm{O}_{2}$ addition. This process, demonstrated with pure cultures and in laboratory studies with sediment, known as co-metabolism, is the main path for oxidation of PCBs (Focht \& Brunner 1985). Biphenyl, acetate, carbohydrates and even other PCB congeners are among the sub- strates supporting co-metabolism of PCBs (Ahmed \& Focht 1973; Furukawa \& Chakarbarty 1982; Massé et al. 1984; Clark et al.1979). Therefore, the in situ degradation of PCBs in sediments might depend not only on the presence of oxygen, but also on the availability of one or more of these organics. Such dependency has been established in one case for anaerobic dechlorination (Nies \& Vogel 1990). Another explanation is that strong sorption of PCBs on the sediment matrix renders a fraction of that $\mathrm{PCB}$ not accessible to microbes over the time period of these studies. This process might explain the persistence of certain PCB congeners in environments with old contamination history. It is noteworthy that added rather than "weathered" PCBs were used in this study. Therefore, is it likely that bioavailability was not a limiting factor. However, no experimental evidence yet defines the required conditions for the successful dechlorination of weathered PCBs.

Operational considerations might also affect the feasibility of the proposed in situ technique. In nature, dechlorination of PCBs is a slow process measured in terms of decades, whereas bioremediation aims at accelerating the naturally-occurring processes while maintaining the cost-effectiveness of the technique. Pilot and field studies are needed to assess the feasibility of this anaerobic-aerobic sequential process for actual sites.

\section{Acknowledgements}

The authors would like to thank Loring Nies for useful discussions. This work work was funded in part by General Electric Company (Grant \# 920347), US EPA Hazardous Substance Research Center (HRSC, Grant \# R-815750-02) and National Institute of Environmental Health and Sciences (NIEHS, Grant \# ES 04911).

\section{References}

Abramowicz DA, Brown JF \& O'Donnell MK (1991) Anaerobic Dechlorination in Hudson River Sediments. General Electric Company Research and Development Program for the De- 
struction of PCBs, Tenth Progress Report. General Electric Corporate Research and Development, Schenectady, NY. Ch 2: $17-30$

Ahmed M \& Focht DD (1973) Degradation of polychlorinated biphenyls by two species of Achromobacter. Can. J. Microbiol. 19: $47-52$

Anid PJ, Nies L \& Vogel TM (1991) Sequential anaerobic-aerobic biodegradation of PCBs in the river model. In: Hinchee RE \& Olfenbuttel RF (Eds) On-site Bioreclamation (pp 428436). Butterworth-Heinemann, Stoneham, MA

Bedard DL, Haberl ML, May RJ \& Brennan MJ (1987) Evidence of novel mechanisms of polychlorinated biphenyl metabolism in Alcaligenes eutrophus H850. Appl. Environ. Microbiol. 53: 1103-1112

Bedard DL, Unterman R, Bopp LH, Brennan MJ, Haberl ML \& Johnson C (1986) Rapid assay for screening and characterizing microorganisms for the ability to degrade polychlorinated biphenyls. Appl. Environ. Microbiol. 51: 761-768

Bopp RF, Simpson HG, Deck BL \& Kostyk N (1984) The persistence of PCB components in sediments of the Lower Hudson. Northeast. Environ. Sci. 3: 179-183

Bopp RF, Simpson HG, Olsen CR \& Kostyk N (1981) Polychlorinated biphenyls in the sediments of the tidal Hudson. Environ. Sci. Technol. 15: 210-216

Britton LN (1985) Feasibility Studies on the Use of Hydrogen Peroxide to Enhance Microbial Degradation of Gasoline. Am. Pet. Inst., Washington, DC, API Publ. no. 4389, $36 \mathrm{p}$

Brown JF Jr, Wagner RE, Bedard DL, Brennan MJ, Carnahan JC, Feng H \& Wagner RE (1984) PCB transformations in Upper Hudson sediments. Northeast. Environ. Sci. 3: 167-179

Brown JF Jr, Wagner RE, Feng H, Bedard DL, Brennan MJ, Carnahan JC \& May RJ (1987) Environmental dechlorination of PCBs. Environ. Toxicol. Chem. 6: 579-593

Brown MP, Werner MB, Sloan RJ \& Simpson KW (1985) Polychlorinated biphenyls in the Hudson River. Environ. Sci. Technol. 19: 656-661

Clark RR, Chian ESK \& Griffin RA (1979) Degradation of polychlorinated biphenyls by mixed microbial cultures. Appl. Environ. Microbiol. 37: 680-685

Focht DD \& Brunner W (1985) Kinetics of biphenyl and polychlorinated biphenyl metabolism in soil. Appl. Environ. Microbiol. 50: 1058-1063

Furukawa K \& Chakrabarty AM (1982) Involvement of plas- mids in total degradation of chlorinated biphenyls. Appl. Environ. Microbiol. 44: 619-626

Furukawa K, Tomizuka N \& Kamibayashi A (1979) Effect of chlorine substitution on the bacterial metabolism of various polychlorinated biphenyls. Environ. Microbiol. 38: 301-310

Furukawa K, Tomizuka N \& Kamibayashi A (1983) Metabolic breakdown of kaneclors (polychlorinated biphenyls) and their products by Acinetobacter sp. Appl. Environ. Microbiol. 46: $140-145$

Furukawa K, Tomizuka N \& Kamibayashi A (1979) Metabolic breakdown of kaneclors (polychlorinated biphenyls) and their products by Acinetobacter sp. Appl. Environ. Microbiol. 47: 947-951

Massé R, Messier F, Péloquin L, Ayotte C \& Sylvestre M (1984) Microbial biodegradation of 4-chlorobiphenyl, a model compound of chlorinated biphenyls

National Academy of Sciences (1979) Polychlorinated Biphenyls. National Academy of Sciences, Washington, D.C. $181 \mathrm{p}$

Nies L \& Vogel TMV (1990) Effects of organic substrates on dechlorination of Aroclor 1242 in anaerobic sediments. Appl. Environ. Microbiol. 56: 2612-2617

Pardieck DL, Bower EJ \& Stone AT (1990) Hydrogen peroxide as a source of oxidant capacity for the transformation of benzene, toluene and xylene in biofilms. In: O'Melia C (Ed) Environmental Engineering, Proceedings of the 1990 Specialty Conference (pp 347-381). Publisher American Society of Civil Engineers, New York, NY

Pardieck DL, Bower EJ \& Stone AT (1992) Hydrogen peroxide use to increase oxidant capacity for in situ bioremediation of contaminated soils and aquifers: a review. J. Comtam. Hydrol. 9: $243-269$

Quensen JF, Tiedje JM \& Boyd SA (1988) Reductive dechlorination of the polychlorinated biphenyls by anaerobic microorganisms from sediments. Science. 242: 752-754

Safe S, Bandiera S, Sawyer T, Robertson L, Safe L, Parkinson A, Thomas PE, Ryan DE, Reik LM, Levin W, Denomme MA \& Fujita T (1985) PCBs: Structure-Function Relationships and Mechanisms of Action. Environ. Health Perspect. 60: 47-56

Vogel TM, Criddle CS \& McCarty PL (1987) Transformations of halogenated aliphatic compounds. Environ. Sci. Technol. 21: $722-736$

Weaver G (1984) PCB Contamination in and around New Bedford. Environ. Sci. Technol. 22A-27A 